Research Paper

\title{
High Serum Lactate Dehydrogenase adds Prognostic Value to Cardiac Biomarker Staging System for Light Chain Amyloidosis
}

\author{
Haiyan He\#, Jin Liü, Hua Jiang, Juan Du, Lu Li, Jing Lu, Weijun Fu ${ }^{凶}$ \\ Myeloma and Lymphoma Center, Department of Hematology, Changzheng Hospital, Shanghai, China \\ \# Contributed equally \\ $\triangle$ Corresponding author: Weijun Fu, Myeloma and Lymphoma Center, Department of Hematology, Changzheng Hospital, 415 Fengyang Road, Shanghai, \\ 200003, China. Tel: +86 21 81885421; E-mail: fuweijun@smmu.edu.cn \\ (C) The author(s). This is an open access article distributed under the terms of the Creative Commons Attribution License (https://creativecommons.org/licenses/by/4.0/). \\ See http://ivyspring.com/terms for full terms and conditions.
}

Received: 2018.10.01; Accepted: 2019.08.07; Published: 2019.09.07

\begin{abstract}
Objective: To evaluate the impact of elevated serum lactate dehydrogenase (LDH) on prognosis of immunoglobulin light chain $(\mathrm{AL})$ amyloidosis, and to investigate its prognostic value for the cardiac biomarker staging system.

Patients and Methods: We analyzed 83 consecutive patients with newly diagnosed immunoglobulin light chain amyloidosis who were treated with bortezomib or thalidomide based therapies between August 2010 and May 2017.

Results: Elevated serum LDH was identified to be associated with cardiac involvement, BNP and TNT $(p=0.017, p=0.007$, and $p=0.026$, respectively). The prognosis of patients with elevated serum LDH was inferior to that of patients with normal serum LDH. The two-year PFS rates of patients with elevated serum LDH and patients with normal serum LDH were $47.8 \%$ and $68.8 \%$ respectively $(p=0.009)$, and the corresponding two-year OS rates were $51.5 \%$ and $73.9 \%$ respectively $(p=0.007)$. We then incorporated serum $\mathrm{LDH}$ into the cardiac biomarker staging system involving cTNT and NT-proBNP. Patients were assigned a score of 1 of cTNT $\geq 0.025 \mathrm{ng} / \mathrm{ml}$, NT-proBNP $\geq 332 \mathrm{ng} / \mathrm{L}$, and LDH $\geq 259 \mathrm{U} / \mathrm{L}$, creating a stage I to IV with scores 0 to 3 points, respectively. The proportion of patients with stage I, II, III, and IV were $31.6 \%, 32.9 \%, 21.1 \%$, and $14.4 \%$. The two-year PFS rates for patients in stage I, II, III and IV were 72.6\%, 53.6\%, 33.7\% and 20\% $(\mathrm{p}<0.001)$, respectively. The two-year OS rates of patients were $90.9 \%, 66.7 \%, 42.9 \%$, and $20 \%(p<0.001)$, respectively.

Conclusion: Elevated LDH had adverse influence on prognosis of $\mathrm{AL}$ amyloidosis, which added prognostic value to the cardiac biomarker staging system.
\end{abstract}

Key words: Light chain amyloidosis; Lactate dehydrogenase; Prognosis

\section{Introduction}

Immunoglobulin light chain (AL) amyloidosis is one of plasma dyspraxia associated disease with deposition of immunoglobulin-derived amyloid in multiple organs [1,2]. The outcome of patients with $\mathrm{AL}$ amyloidosis is highly dependent on the spectrum and severity of organ involvement, especially at cardiac level [3]. Significant variability exists in the outcome among patients with similar clinical presentation. Soluble cardiac biomarkers including tropnin-T and NT-proBNP have been acknowledged as the best prognosis predictor of $\mathrm{AL}$ amyloidosis
[4-6]. In 2004 the cardiac biomarker staging system was firstly reported by Mayo clinic which including serum levels of cardiac troponins (troponin T [cTnT]) and N-terminal propeptide (NT-ProBNP) [7]. The level of serum free light chain was also been found as an adverse prognostic factor of amyloidosis, which indicates that the risk stratification of patients depends not only on the burden of amyloid in the tissue (especially the heart) but also the size of plasma cells in bone marrow and its biology. To further identify risks of the patients, in 2012, Mayo clinic 
updated the staging system by incorporating serum free light chain into the cardiac biomarker staging system [8]. However, there are still some other prognostic factors to be identified for further risk stratification of AL amyloidosis.

The prognostic value of lactate dehydrogenase is well understood in aseries of malignant neoplasms, especially in multiple myeloma and lymphoma. Elevated $\mathrm{LDH}$ ( $\mathrm{LDH} \geq$ upper limit of normal) is an important adverse indicator for survival of high-grade lymphoma and a parameter in the International Prognostic Lymphoma Index [9]. In myeloma, elevated LDH is associated with lower response and shorter survival. It has been added to Revised International Staging System(R-ISS) of multiple myeloma as an important prognostic factor [10]. In clinical practice, we observed a large portion of patients with AL amyloidosis also had an elevated LDH level. To evaluate the prognostic influence on AL amyloidosis and to investigate its prognostic value to the cardiac biomarker staging system, we retrospectively analyzed 83 patients, reported as below.

\section{Patients and Methods}

\section{Patients}

Between August 2010 and October 2016, a total of 83 patients with AL amyloidosis were investigated. Of these patients, 40 cases were associated with multiple myeloma. At least one biopsy specimen from endomyocardial tissue, kidney, rectum, bone marrow or subcutaneous fat was positive of amyloid, and the presence of amyloid was visualized by Congo red staining, producing apple-green birefringence under polarized light. Organ systemic involvement was defined by laboratory and clinical manifestations of renal, cardiac, hepatic gastrointestinal, neuropathic, pulmonary, or soft tissue involvement according to 2005 consensus criteria [11]. All patients were provided written informed consent for this study. Approval was obtained by the ethics committee of the Shanghai Changzheng Hospital.

\section{Laboratory methods}

Serum lactate dehydrogenase activity was determined by using Ectachem clinical chemistry slides with a multipoint rate slides test (Johnson \&Johnson Clinical Diagnositic, USA) on Ectachem 259 analyzer.

Assays for cTnT was performed by sensitive second- and third-generation assays with reagents provided by Roche Diagnostics (Indianapolis, IN) and DADE (Newark, DE). The troponin T assay has a limit of detection of less than $0.01 \mathrm{~g} / \mathrm{L}$ and coefficients of variability of $10 \%$ at $0.035 \mathrm{~g} / \mathrm{L}$ and $20 \%$ at $0.015 \mathrm{~g} / \mathrm{L}$
(Roche Diagnostics). The value of $0.035 \mathrm{~g} / \mathrm{L}$ is the lowest value that meets the European Society of Cardiology/American College of Cardiology (ESC/ACC) criteria for precision. NT-proBNP levels were measured with electrochemilumi-nescence sandwich immunoassay (ECLIA; Roche) on an Elecsys System 2010.

\section{The Cardiac Biomarker Staging System}

For patients with unavailable results of serum free light chain, the cardiac biomarker staging system involving NT-proBNP and troponin $\mathrm{T}$ levels was used. In this system threshold values were chosen (cTnT0.035 g/L; and NT-proBNP332 ng/L). Patients are considered stage I (low risk) when both troponin and NT-proBNP are below the threshold, stage II (intermediate risk) if only one marker is below the threshold, and stage III (high risk) if both are no less than the threshold.

\section{Treatment}

Among the 83 newly diagnosed patients, 68 patients were treated with bortezomib-based regimen as induction therapy, and 15 patients were treated with thalidomide-based regimen as induction therapy.

\section{Statistical analysis}

SPSS (IBM, version 16.0, New York, NY, USA) was employed to perform all analysis. Comparison among groups and comparison between two groups were performed by one-way ANOVA and chi-square test respectively. Survival analysis was performed using Kaplan-meier method. Differences were considered significant when the $p$-value was less than 0.05. OS was defined as the time from diagnosis to death for any cause, and PFS was defined as the time from the initiation of therapy to disease progression, relapse, and death for any cause.

\section{Results}

\section{Patient characteristics}

Baseline clinical characteristics of the 83 patients were shown in Table 1 . The median age of the patients was 61 (range, 36-82), and $62(74.7 \%)$ patients were male. $43(51.8 \%)$ patients were primary AL amyloidosis and the other $40(48.2 \%)$ patients were with multiple myeloma. $57(68.7 \%)$ patients had cardiac involvement, $65(78.3 \%)$ patients had renal involvement with levels of proteinuria over or equivalent to $500 \mathrm{mg}$, and $16(19.2 \%)$ patients had renal insufficiency with elevated levels of serum creatinine over or equivalent to $176 \mathrm{mmol} / \mathrm{L}$. According to the Mayo cardiac biomarker staging system (2004), all patients had the two available 
variables with 33 patients in stage I, 31 patients in stage II, and 19 patients in stage III, respectively. FISH abnormalities were detected in 66 patients. The incidence rates of $\mathrm{t}(11 ; 14), \mathrm{t}(4 ; 14), 17 \mathrm{p}-, 13 \mathrm{q}-, 1 \mathrm{q} 21+$ were $15.2 \%, 12.1 \%, 4.5 \%, 30.3 \%$, and $43.9 \%$, respectively.

Table 1. The correlation between serum LDH and other clinical characteristics.

\begin{tabular}{|c|c|c|c|c|}
\hline & $\begin{array}{l}\text { All patients } \\
(\mathrm{n}=83)\end{array}$ & $\begin{array}{l}\text { Patients with } \\
\text { High serum } \\
\text { LDH }(n=38)\end{array}$ & $\begin{array}{l}\text { Patients with } \\
\text { Normal serum } \\
\text { LDH }(n=45)\end{array}$ & $P$ value \\
\hline $\begin{array}{l}\text { Age (median, range), } \\
\text { years }\end{array}$ & $61,36-82$ & $59,42-76$ & $61,36-82$ & 0.506 \\
\hline \multicolumn{5}{|l|}{ Gender } \\
\hline Male,\%(n) & $74.7(62)$ & $65.8(25)$ & $82.2(37)$ & 0.072 \\
\hline \multicolumn{5}{|l|}{ Involved organ,\%(n) } \\
\hline Cardiac & $68.7(57)$ & $81.6(31)$ & $57.8(26)$ & 0.017 \\
\hline kidney & $78.3(65)$ & $76.3(29)$ & $80(36)$ & 0.443 \\
\hline Primary,\%(n) & $51.8(43)$ & $(18 / 38)$ & $(25 / 45)$ & \\
\hline AL with MM, \%(n) & $48.2(40)$ & $(20 / 38)$ & $(20 / 45)$ & 0.513 \\
\hline $\begin{array}{l}\text { Renal disfunction, } \\
\%(\mathrm{n})\end{array}$ & $19.3(16)$ & $26.3(10)$ & $13.3(6)$ & 0.168 \\
\hline $\begin{array}{l}\text { HGB, median (range) } \\
\text { g/L }\end{array}$ & $112(51-163)$ & 113(70-163) & $110(51-150)$ & 0.410 \\
\hline $\begin{array}{l}\mathrm{BNP} \text {, median (range) } \\
\mathrm{pg} / \mathrm{ml}\end{array}$ & $\begin{array}{l}1558 \\
(48.4-33400)\end{array}$ & $\begin{array}{l}4650 \\
(60.3-33400)\end{array}$ & 844 (48.4-9680) & 0.007 \\
\hline $\begin{array}{l}\text { c-TNT (median, } \\
\text { range), } \mathrm{ng} / \mathrm{ml}\end{array}$ & $0.02(0-1.55)$ & $0.18(0-1.55)$ & $0.01(0-0.48)$ & 0.026 \\
\hline $\begin{array}{l}\text { Beta2-MG (median, } \\
\text { range) }\end{array}$ & 3.91(1.13-19.24) & $5.1(1.54-19.24)$ & $3.24(1.13-16.52)$ & 0.061 \\
\hline \multicolumn{5}{|l|}{$\begin{array}{l}\text { Mayo stage (2004), \% } \\
\text { (n) }\end{array}$} \\
\hline I & $39.8(33)$ & $21.1(8)$ & $55.6(25)$ & \\
\hline II & $37.3(31)$ & $44.7(17)$ & $28.8(13)$ & \\
\hline III & $2.8(19)$ & $34.2(13)$ & $15.6(7)$ & 0.004 \\
\hline \multicolumn{5}{|l|}{ FISH } \\
\hline $\mathrm{t}(11 ; 14)$ & 15.2(10/66) & $14.3(5 / 35)$ & $16.1(5 / 31)$ & 0.501 \\
\hline $\mathrm{t}(4 ; 14)$ & $12.1(8 / 66)$ & $11.4(4 / 35)$ & $12.9(4 / 31)$ & 0.530 \\
\hline $17 p-$ & $4.5(3 / 66)$ & $2.9(1 / 35)$ & $6.5(2 / 31)$ & 0.902 \\
\hline $13 q-$ & $30.3(20 / 66)$ & $25.7(9 / 35)$ & $35.5(11 / 31)$ & 0.276 \\
\hline $1 \mathrm{q} 21+$ & $43.9(29 / 66)$ & $51.4(18 / 35)$ & $35.5(11 / 31)$ & 0.146 \\
\hline
\end{tabular}

The correlation between serum LDH and other clinical and laboratory parameters was investigated. Serum LDH was associated with the level of serum tropnin-T and NT-proBNP. The median value of

A

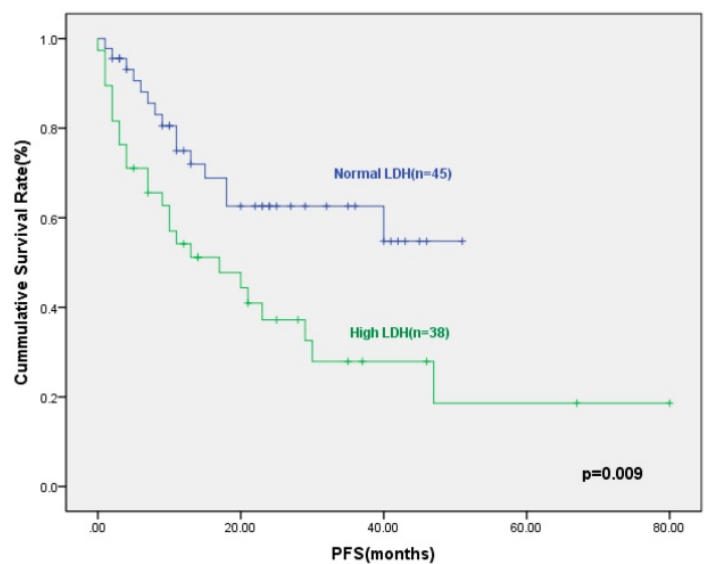

c-TNT in patients with elevated level of serum LDH was $0.18(0-1.55) \mathrm{ng} / \mathrm{ml}$, which was significantly higher than that of $0.01(0-0.048) \mathrm{ng} / \mathrm{ml}$ in patients with normal level serum LDH $(p=0.026)$. The median value of NT-proBNP in patients with elevated level of serum LDH was 4650 (60.3-33400) pg/ml, which was significantly higher than that of $844(48.4-9680) \mathrm{pg} / \mathrm{ml}$ in patients with normal level serum LDH ( $p=0.007)$. Accordingly the Mayo 2004 staging system incorporating NT-proBNP and troponin levels was also found to be correlated with serum LDH. 34.2\% $(13 / 38)$ patients with elevated level serum LDH were in stage III, which was significantly higher than that of $15.6 \%(7 / 45)$ in patients with normal level LDH $(p=0.004)$. Cardiac involvement, defined by the level of NT-proBNP and echocardiography, was also found to be associated with serum LDH. 81.6\% (31/38) patients with high serum LDH had cardiac involvement, which was significantly higher than that of $57.8 \%(26 / 45)$ in patients with normal level serum $\mathrm{LDH}(\mathrm{p}=0.005)$. Other clinical parameters such as age, gender, hemoglobin, $\beta 2-\mathrm{MG}$, renal involvement and FISH results, have not found to be correlated with serum LDH.

\section{Survival and prognosis}

At a median follow-up of 16 (range,3-80) months, $32(38.6 \%)$ patients died, 11 from the normal serum LDH group and 21 from the high-level serum $\mathrm{LDH}$ group, and the relative risk was 2.26. The two-year progression free survival (PFS) rates for patients with normal serum $\mathrm{LDH}$ and high-level serum $\mathrm{LDH}$ were $68.8 \%$ and $47.8 \%$ respectively $(p=0.009)$ (Figure 1A), and the two-year overall survival (OS) rates for patients with normal serum LDH and high-level serum LDH were $73.9 \%$ and $51.5 \%$, respectively $(p=0.007)$ (Figure $1 B)$.

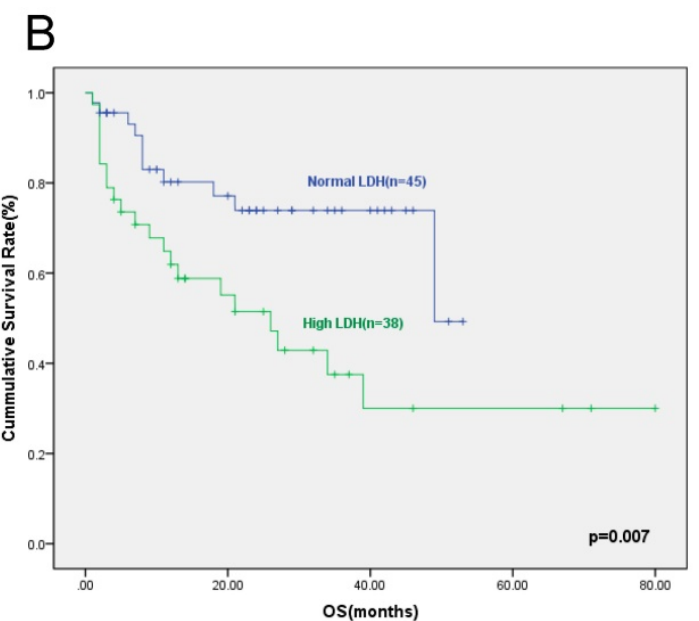

Figure 1. The progression free survival (A) and overall survival (B) according to normal or high serum LDH level. The two-year PFS rates for patients with normal serum LDH and high-level serum LDH were $68.8 \%$ and $47.8 \%(p=0.009)$, and the two-year OS rates for patients with normal serum LDH and high-level serum LDH were $73.9 \%$ vs $51.5 \%(p=0.007)$. 

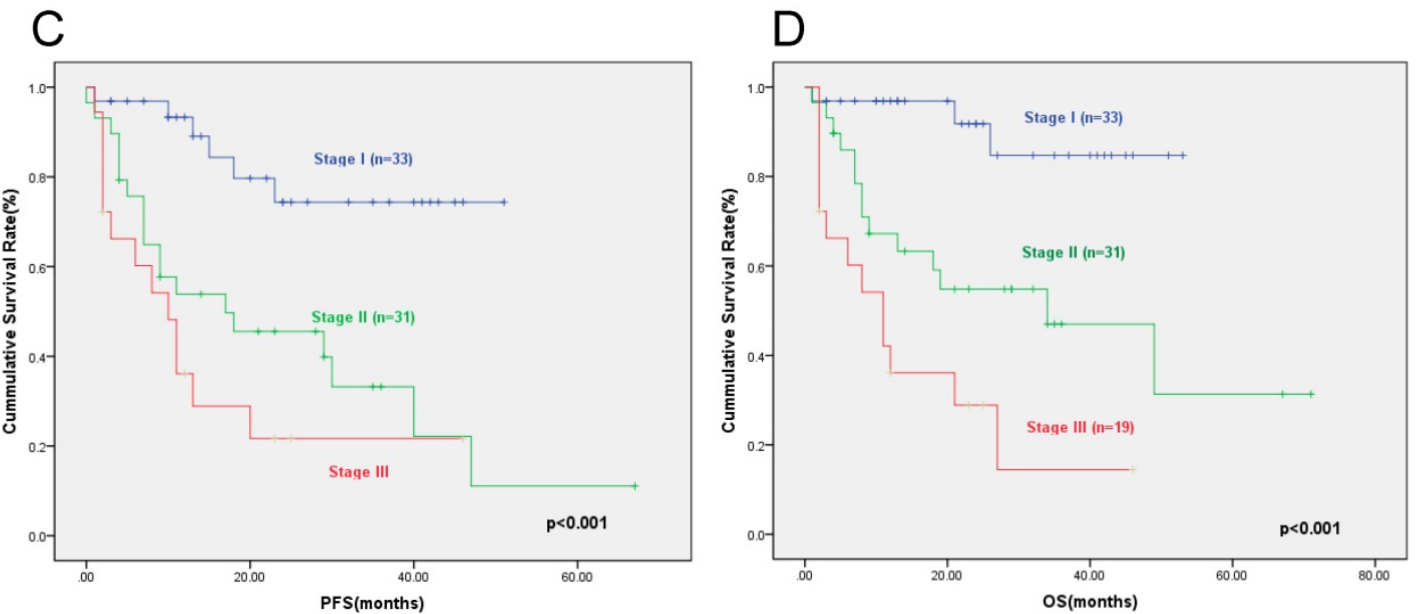

Figure 2. The progression free survival (C) and overall survival (D) according to the cardiac biomarker staging system. The two-year PFS rates for patients in stage I, II, and III were $74.4 \%, 45.6 \%$, and $21.7 \%$ respectively $(P<0.001)$, and the two-year OS rates were $84.7 \%, 47.0 \%$, and $28.9 \%$ respectively $(P<0.001)$.
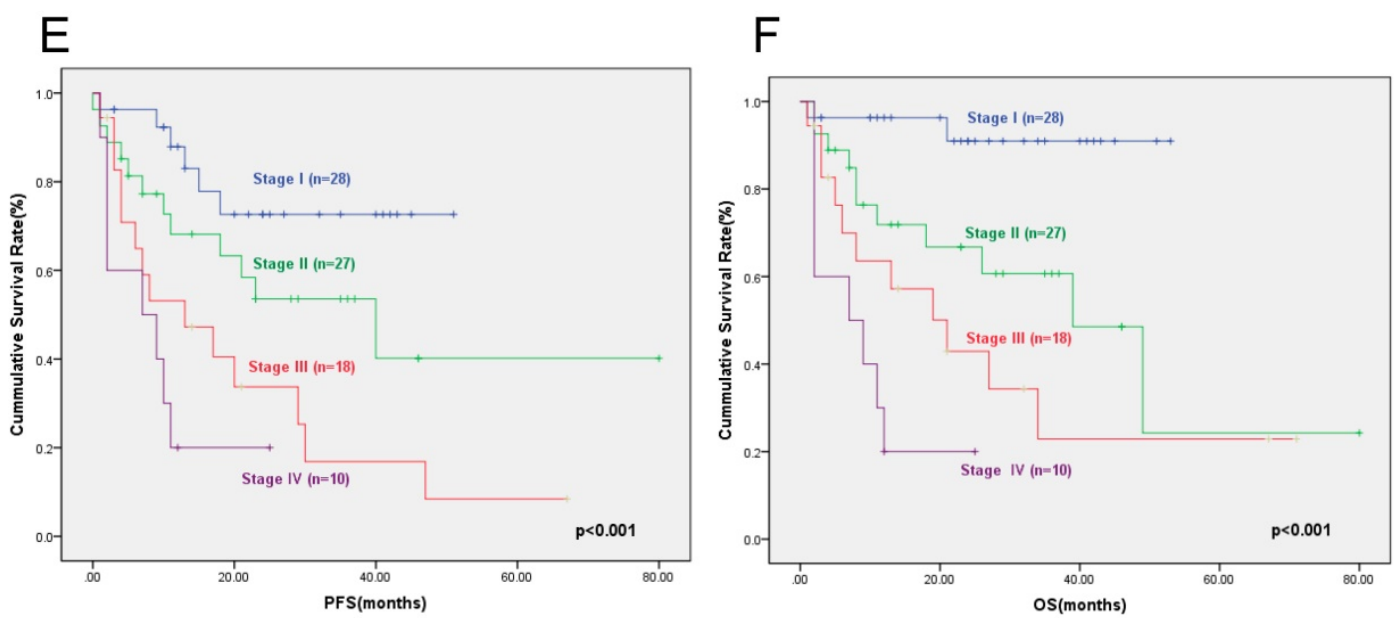

Figure 3. The progression free survival $(\mathrm{E})$ and overall survival $(\mathrm{F})$ according to the new staging system (incorporating serum LDH to the cardiac biomarker staging system).The two-year PFS rates for patients in stage I, II, III, and IV were 72.6\%, 53.6\%,33.7\%, and 20\% ( $\mathrm{p}<0.001$ ) (Figure 3E), and the two-year OS rates were $90.9 \%, 66.7 \%, 42.9 \%$, and $20 \%$ $(p<0.001)$ (Figure 3F).

According to the Mayo cardiac biomarker staging system (2004), all patients had available NT-proBNP and cTNT results with 33 patients in stage I, 31 patients in stage II, and 19 patients in stage III, respectively. The two-year PFS rates for patients in stage I, stage II, and stage III were $74.4 \%, 45.6 \%$ and $21.7 \%$ respectively $(p<0.001)$ (Figure $2 \mathrm{C}$ ). The two-year OS rates for patients in stage I, stage II, and stage III were $84.7 \%, 47.0 \%$ and $28.9 \%$ respectively $(p<0.001)$ (Figure 2D).

To identify the patients with the worst prognosis, we incorporated serum LDH into the cardiac biomarker staging system. Patients were assigned a score of 1 of $c T N T \geq 0.025 \mathrm{ng} / \mathrm{ml}$, NT-proBNP332 $\geq \mathrm{ng} / \mathrm{L}$, and $\mathrm{LDH} \geq 259 \mathrm{U} / \mathrm{L}$, creating a stage I to IV with scores 0 to 3 points, respectively. The number of patients in stage I, II, III, and IV were $28,27,18$, and 10. and the two-year PFS rates for patients in stage I, II, III, and IV were $72.6 \%$, $53.6 \%, 33.7 \%$, and $20 \%$ respectively $(\mathrm{p}<0.001)$ (Figure
3E). The two-year OS rates for patients in stage I, II, III, and IV were $90.9 \%, 66.7 \%, 42.9 \%$, and $20 \%$ respectively $(\mathrm{p}<0.001)$ (Figure $3 \mathrm{~F})$.

\section{Discussion}

AL amyloidosis is characterized by a relatively low burden of clonal plasma cells and involvement of multiple organs by immunoglobulin light chain-derived fibrils. The outcome of patients with AL amyloidosis is heterogeneous, and the median OS from diagnosis among all patients is approximately 1 year [12]. Outcome of the disease is related to a series of factors. Cardiac involvement is the most significantly adverse predictor of survival. Hence, the mayo staging system (2004) for light chain amyloidosis adopted the of use serum levels of cardiac troponins (that is, troponin $\mathrm{T}[\mathrm{cTnT}]$ or I) as well as brain natriuretic peptide (BNP) and its $\mathrm{N}$-terminal propeptide [7]. According to this staging system, the median survivals of patients in stages I, II, 
and III, were 26.4, 10.5, and 3.5 months, respectively. To assess the prognosis of AL amyloidosis more accurately and potentially select the optimal therapy, a new staging system incorporating both cardiac biomarkers and serum FLC measurements for AL amyloidosis was developed in 2012 [8]. The median OS of patients with stages I, II, III and IV disease from diagnosis was 94.1, 40.3, 14.0, and 5.8 months, respectively. Compared with the previous staging system, the revised mayo staging system was more developed by adding the level of clonal plasma cells because the underlying abnormality in $\mathrm{AL}$ amyloidosis is the clonal plasma cell. However, there were still prognostic factors needed to be identified to further stratify the patients.

In this study, we found that serum LDH level was also an adverse prognostic factor of $\mathrm{AL}$ amyloidosis. It is known that lactate dehydrogenase is a glycolytic enzyme which exists in all normal tissue cells as well as in tumor cells. Elevated serum LDH is a marker for tissue injury, inflammation, hemolysis and myocardial infarction [13-15], whose prognostic value has been shown in several malignancies such as germ cell tumors, lymphoma, melanoma and renal cell carcinoma [16-19]. In this study, we found a total of $45.8 \%$ patients with AL amyloidosis had elevated serum LDH level. It needs to be further cleared whether the elevated serum LDH level indicted the degree of organ involvement or the number of clonal plasma cells. A significant correlation of elevated $\mathrm{LDH}$ with cardiac biomarker was also identified, which indicated the addition of $\mathrm{LDH}$ as a marker of tissue injury in $\mathrm{AL}$ amyloidosis. It is known that there are five types of LDH Isoenzymes, LDH1, LDH2, LDH3, LDH4, and LDH5 respectively. The serum LDH1 and LDH2 would be significantly upregulated in case of myocardial injury. Next, we should detect $\mathrm{LDH}$ Isoenzymes and check the relation of each of Isoenzymes with the prognosis of $\mathrm{AL}$ amyloidosis. Palladini et al. have demonstrated in a small set of patients that reductions in NT-proBNP occur in majority of patients who enjoy a hematologic response [20]. As serum LDH is also a valuable predictor of overall survival in patients, serum LDH could be a potential probable response evaluating parameter in AL amyloidosis.

In this study we developed a novel framework by incorporating the serum $\mathrm{LDH}$ to the cardiac biomarker staging system. With this framework the highest risk patients are clearly separated from the lower risk patients. The highest risk patients with three high-risk factors (cTNT $\geq 0.025 \mathrm{ng} / \mathrm{ml}$, NT-proBNP332 $\geq$ ng/L, and LDH $\geq 259 \mathrm{U} / \mathrm{L}$ ) had one-year survival rate of $18 \%$. The separation of stage II and stage III is less dramatic than that in the Mayo cardiac staging system (2004). Using this system, we found a good separation between I, II, III and IV stage. Our study is limited to a relative small number of patients (83 cases) and short follow-up (median 16 months). Validations in other datasets with larger numbers of patients and longer follow-up would be sufficient for the poor prognosis of $\mathrm{LDH}$ in $\mathrm{AL}$ amyloidosis.

\section{Acknowledgements}

\section{Ethical approval}

All procedures performed in studies involving human participants were in accordance with the ethical standards of the institutional and/or national research committee and with the 1964 Helsinki declaration and its later amendments or comparable ethical standards.

\section{Informed consent}

Informed consent was obtained from all individual participants included in the study.

\section{Competing Interests}

The authors have declared that no competing interest exists.

\section{References}

1. Falk, R. H., Comenzo, R. L., \& Skinner, M.. The systemic amyloidoses. New England Journal of Medicine. 1997; 337(13): 898-909.

2. Gertz, M. A.. Immunoglobulin light chain amyloidosis: 2011 update on diagnosis, risk-stratification, and management. American Journal of Hematology. 2011; 86(2): 180-186.

3. Kyle, R. A., Greipp, P. R., \& O'Fallon, W. M.. Primary systemic amyloidosis: multivariate analysis for prognostic factors in 168 cases. Blood. 1986; 68(1): 220-4

4. Dispenzieri, A., Gertz, M. A., Kyle, R. A., et al. Prognostication of survival using cardiac troponins and n-terminal pro-brain natriuretic peptide in patients with primary systemic amyloidosis undergoing peripheral blood stem cell transplantation. Blood. 2004; 104(104): 1881-1887.

5. Dispenzieri, A., Kyle, R. A., Gertz, M. A., et al. Survival in patients with primary systemic amyloidosis and raised serum cardiac troponins. Lancet. 2003; 361(9371): 1787-1789.

6. Palladini, G., Campana, C., Klersy, C., et al. Serum n-terminal pro-brain natriuretic peptide is a sensitive marker of myocardial dysfunction in al amyloidosis. Circulation. 2003; 107(19): 2440.

7. Dispenzieri, A., Gertz, M. A., Kyle, R. A., et al. Serum cardiac troponins and n-terminal pro-brain natriuretic peptide: a staging system for primary systemic amyloidosis. Journal of Clinical Oncology Official Journal of the American Society of Clinical Oncology. 2004; 22(18): 3751-7.

8. Kumar, S., Dispenzieri, A., Lacy, M. Q., et al. Revised prognostic staging system for light chain amyloidosis incorporating cardiac biomarkers and serum free light chain measurements. Journal of Clinical Oncology. 2012; 30(9): 989-995.

9. Factors, A. A predictive model for aggressive non-hodgkin's lymphoma. the international non-hodgkin's lymphoma prognostic factors project. N Engl J Med. 1993; 329(14): 987-94.

10. Palumbo, A., Avet-Loiseau, H., Oliva, S., et al. Revised international staging system for multiple myeloma: a report from international myeloma working group. Journal of Clinical Oncology. 2015; 33(26): 2863-2869.

11. Gertz, M. A., Comenzo, R., Falk, R. H., et al. Definition of organ involvement and treatment response in immunoglobulin light chain amyloidosis (al): a consensus opinion from the 10th international symposium on amyloid and amyloidosis, tours, france, 18-22 april 2004. American Journal of Hematology. 2010; 79(4): 319-328.

12. Gertz, M. A. Immunoglobulin light chain amyloidosis: 2011 update on diagnosis, risk-stratification, and management. American Journal of Hematology. 2011; 86(2): 180-186. 
13. Drent, M., Cobben, N. A., Henderson, R. F., et al. Usefulness of lactate dehydrogenase and its isoenzymes as indicators of lung damage or inflammation. European Respiratory Journal. 1966; 9(8): 1736-1742.

14. Kemp, M., Donovan, J., Higham, H., et al. Biochemical markers of myocardial injury. British Journal of Anaesthesia. 2004; 93(1): 63-73.

15. Kato, G. J., Mcgowan, V., Machado, R. F., et al. Lactate dehydrogenase as a biomarker of hemolysis-associated nitric oxide resistance, priapism, leg ulceration, pulmonary hypertension, and death in patients with sickle cell disease. Blood. 2006; 107(6): 2279.

16. Balch, C. M., Soong, S. J., Atkins, M. B., et al. An evidence-based staging system for cutaneous melanoma. Ca A Cancer Journal for Clinicians. 2010; 54(3): 131-149.

17. Barlow, L. J., Badalato, G. M., Mckiernan, J. M. Serum tumor markers in the evaluation of male germ cell tumors. Nature Reviews Urology. 2010; 7(11): 610-617.

18. Armstrong, A. J., George, D. J., Halabi, S. Serum lactate dehydrogenase predicts for overall survival benefit in patients with metastatic renal cell carcinoma treated with inhibition of mammalian target of rapamycin. Journal of Clinical Oncology Official Journal of the American Society of Clinical Oncology. 2012; 30(27): 3402

19. Nagle, S. J., Woo, K., Schuster, S. J., et al. Outcomes of patients with relapsed/refractory diffuse large b-cell lymphoma with progression of lymphoma after autologous stem cell transplantation in the rituximab era. American Journal of Hematology. 2013; 88(10): 890-894.

20. Palladini, G., Campana, C., Klersy, C., et al. Serum n-terminal pro-brain natriuretic peptide is a sensitive marker of myocardial dysfunction in al amyloidosis. Circulation. 2003; 107(19): 2440 